\title{
Design da informação e a inovação no judiciário: estudo de caso em uma Vara de Saúde Pública
}

\author{
Information design and innovation in the judiciary: \\ a case study in a Public Health Court
}

\author{
Lívia F. de Albuquerque Campos, Fabiane Rodrigues Fernandes, \\ Francisco H. Garces de Albuquerque
}

design da Informação, infografia, inovação no serviço público.

A judicialização da saúde consiste no acionamento do Poder Judiciário para o fornecimento de medicamentos, insumos e demais tratamentos de saúde ao cidadão (Medrado, Cruz, Raso, \& Rocha, 2013). A partir de setembro de 2016 do Conselho Nacional de Justiça autorizou a criação de varas especializadas para a garantia desse direito (Conselho Nacional de Justiça, 2016). Entretanto, ao momento de sua implantação, severas dúvidas e demandas de conteúdo informacional podem ser verificadas. O presente artigo contempla um estudo de caso em uma Vara de Saúde Pública e aborda como ferramentas do Design da Informação podem mediar conflitos informacionais e contribuir para as novas práticas voltadas para a inovação do serviço judiciário. Para isto foi realizada uma abordagem baseada em etapas propostas por Carvalho \& Aragão (2012) e priorizou a valorização da inteligência coletiva dos servidores. Os resultados contemplam um infográfico desenvolvido com base nas recomendações para o Design da Informação de Pettersson (2010) o qual foi veiculado em suporte digital (smartphones).

information design, infographics, innovation in public service.

The judicialization of health consists of activating the Judiciary to provide medicines, supplies and other health treatments to citizens (Medrado, Cruz, Raso, \& Rocha, 2013) and as of September 2016, the National Council of Justice authorized the creation of specialized courts for the guarantee of this right (CNJ. Conselho Nacional de Justiça., 2016). However, at the time of its implementation, severe doubts and demands for informational content can be verified. This article contemplates a case study in a Public Health Court and discusses how Information Design tools can mediate informational conflicts and contribute to new practices aimed at the innovation of the judicial service. For this, an approach based on steps proposed by Carvalho \& Aragão (2012) was carried out and prioritized the valorisation of the collective intelligence of servants. The results include an infographic developed based on the recommendations for Information Design by Pettersson (2010) which was transmitted in digital (smartphones).

\section{Introdução}

O setor público ainda funciona dentro de uma modelagem desenvolvida há mais de cem anos, cujas marcas centrais destacam-se pela hierarquia, a centralização e a especialização. Entretanto, ao longo do século $X X$, essa engrenagem foi progressivamente perdendo sua efetividade ao se defrontar com uma "economia globalizada e sofisticada, centrada no

Anais do $10^{\circ} \mathrm{CIDI}$ e $10^{\circ} \mathrm{CONGIC}$

Kelli C.A.S. Smythe, Rafael de Castro Andrade (orgs.) Sociedade Brasileira de Design da Informação - SBDI Curitiba | Brasil | 2021
Proceedings of the $10^{\text {th }} \mathrm{CIDI}$ and $10^{\text {th }}$ CONGIC

Kelli C.A.S. Smythe, Rafael de Castro Andrade (orgs.)

Sociedade Brasileira de Design da Informação - SBDI Curitiba | Brazil | 2021 
conhecimento e no uso criativo de novas tecnologias e materiais e com uma sociedade articulada em rede, plural e reivindicativa" (Agune \& Carlos, 2019, p. 21).

Segundo Zanoni (2019, p. 47) a corrida pela inovação no sistema de justiça foi sistematizada no movimento de "legal design" na Universidade de Stanford, que busca "potenciais da inovação para criação de novos serviços e organizações jurídicas mais satisfatórios, com a aplicação do design centrado no ser humano no direito". Assim, esta prática consiste em uma contribuição do design no mundo do direito, "para tornar os sistemas e serviços jurídicos mais centrados no ser humano, utilizáveis e satisfatórios"

O design oferece uma maneira de repensar e melhorar a experiência jurídica das pessoas. Isso significa que tanto do ponto de vista do leigo - que tem que navegar no sistema judiciário para lidar com um problema ou buscar a justiça -, como do ponto de vista dos profissionais (advogados, juízes, servidores, dentre outros), o sistema jurídico pode ser mais claro, mais eficiente, mais utilizável e mais amigável (Hagan, s.d.). Para a autora o design com seus métodos centrados no ser humano pode definir métricas importantes para entregar serviços que são utilizáveis, úteis e envolventes.

Dentre estas experiências encontra-se a problemática das questões relacionadas ao direito à saúde. Para Medrado, Cruz, Raso, \& Rocha (2013) ao acionamento do Poder Judiciário para o fornecimento de medicamentos, insumos e demais tratamentos de saúde ao cidadão dá-se o nome de "Judicialização da Saúde".

A judicialização da saúde envolve questões complexas que exigem a adoção de medidas para proferir decisões técnicas e precisas. A partir de 06 de setembro de 2016 do Conselho Nacional de Justiça autorizou através da Resolução n 326 a criação e manutenção, pelos Tribunais de Justiça e Regionais Federais de Comitês Estaduais da Saúde, bem como a especialização de vara em comarcas com mais de uma vara de fazenda (Conselho Nacional de Justiça, 2016)

Tal medida permitiu redistribuir os novos processos para uma nova unidade judiciária que tem a competência para processar e julgar ações relativas ao SUS (Sistema Único de Saúde) quanto à internação hospitalar, cirurgia, fornecimento de medicamentos, órteses e próteses (Poder Judiciário do Estado do Maranhão, 2020).

$\mathrm{Na}$ implementação destas novas especializações, algumas situações de conflito de cunho informacional podem ser verificadas, já que em virtude da complexidade da informação, quando não for bem gerenciada pode ocasionar erros, insatisfação e morosidade na tramitação dos processos. Assim, buscou-se abordar esta problemática a partir da experiência da implantação de uma nova Vara de Saúde Pública e destacar como o design da informação contribuiu na mediação dos conflitos relativos à demanda de cunho informacional. 


\section{Referencial Teórico}

\section{Inovação no serviço público e o papel do Design da Informação}

Segundo Zanoni (2019) até a década de 1990, a administração pública brasileira manteve-se arraigada ao modelo burocrático. A partir daí, a tendência foi a de repensar a função do Estado, movimento impulsionado pelas ondas de desenvolvimento tecnológico. Nos países anglo-saxões, importou-se da iniciativa privada conceitos gerenciais, para imprimir melhores resultados que atendessem o interesse público, movimento cunhado de Nova Gestão Pública. Nos países de tendência mais burocrática, desenvolveu-se o Estado Neo weberiano, que também adotou conceitos para tornar o estado mais profissional, mais eficiente, com análise de desempenho, diálogo com o cidadão para extrair suas necessidades e expectativas.

Agune \& Carlos (2019) comparam o setor privado e o setor público quanto à consequência da queda nos níveis de produtividade. No setor privado, essa queda leva à perda de mercado, à incorporação por outra organização ou, no limite, ao desaparecimento. Já no caso do serviço público, eles não podem falir, entretanto, a persistência em adotar métodos, técnicas e processos que vão se tornando obsoletos acaba por conduzir ao enfraquecimento institucional, à deterioração da gestão pública e à incapacidade de prover serviços adequados à população.

Para os autores, a nova gestão pública demandará o uso métodos, técnicas gerenciais e tecnologias que permitam cuidar de uma agenda mais complexa, interconectada e mutante. Esses desafios imporão uma ampla requalificação do corpo gerencial, calcada na mudança cultural e na aquisição de novas competências, habilidades e atitudes, de modo a alinhá-lo com novas formas de trabalho que valorizam a visão sistêmica, o pensamento crítico, a colaboração, a criatividade e a inovação.

Dick, Gonçalves, \& Vitorino (2017) ressaltam que na sociedade da informação tanto o excesso quanto à falta dessa podem implicar em exclusão de públicos. Por isso, faz-se necessário ser competente na construção da mensagem, identificando falhas na construção da mesma, avaliando, recuperando e reestruturando maneiras de passar a informação. Pettersson (2010) acredita que a insatisfação com a execução de uma mensagem também pode causar insatisfação com o conteúdo da mensagem. Frascara (2015) alerta que um dado em um determinado contexto pode ser considerado informação, mas em outro poderá ser ruído. Assim, o design da informação se mostra relevante, ao lidar em sua essência com a organização e a apresentação da mensagem, transformando-a em informação de valor e significado.

\section{Design da Informação}

A Sociedade Brasileira de Design de Informação acredita que essa área deve considerar o desempenho da interface/sistema, mas também os processos cognitivos e de representação do conhecimento. A Sociedade Brasileira de Design de Informação (2020) define design de informação como:

[..] uma área do design gráfico que objetiva equacionar os aspectos sintáticos, semânticos e pragmáticos que envolvem os sistemas de informação através da contextualização, planejamento, produção e 
interface gráfica da informação junto ao seu público alvo. Seu princípio básico é o de otimizar o processo de aquisição da informação efetivado nos sistemas de comunicação analógicos e digitais.

Quintão \& Triska (2014, p. 111) acreditam que "um bom design de informação convida a ser usado, reduz o cansaço e erros no processamento de informações, acelera o trabalho e faz com que a informação seja atrativa e adequada à situação em que se apresenta". É competência do design de informação atrair e reter a atenção do receptor, se preocupando também com a legibilidade, leiturabilidade e compreensão. Para isso, o conteúdo deve ser apresentado com clareza, organizando e caracterizando informações complexas em diferentes contextos e aplicações.

Tal qual outras áreas do conhecimento, o design de informação é constituído de teoria e prática. Segundo Pettersson (2010, p. 168), assim como uma moeda possui duas faces, o design de informação possui a infologia e a infografia como "faces" de seu domínio. A infologia diz respeito "aos estudos da maneira como uma representação verbo-visual deve ser projetada a fim de alcançar uma comunicação ideal entre o remetente e o receptor", enquanto que a infografia seria "formação e execução real e prática de combinações estruturadas de palavras, imagens e design gráfico".

O design de informação deve unir teoria e prática no projeto de textos compreensíveis, claros e consistentes, de ilustrações elucidativas, além de tipografia e layout claros e transparentes que auxiliem na atenção, percepção, interpretação, compreensão e aprendizagem. Para Lipton (2007) a teoria envolve alguns princípios para organização e leiaute, que estão intimamente relacionados com os princípios da Gestalt (ou Teoria da Forma) como consistência (homogêneo, coeso), proximidade, segmentação ou categorização, alinhamento, hierarquia, equilíbrio, fluxo de leitura, clareza, leiturabilidade e legibilidade. Enquanto que para Pettersson (2010) se baseia em princípios funcionais, administrativos, estéticos e cognitivos.

Destacam-se aqui neste estudo os princípios Funcionais, Estéticos e Cognitivos de Petterson (2010). Dentre os Princípios funcionais encontram-se:

- Definição do Problema: Durante uma fase introdutória de análise e planejamento, é possível organizar o trabalho, analisar o grupo de destinatários pretendidos, suas características específicas e seus requisitos, analisar a mensagem pretendida, coletar e revisar os dados e fatos necessários, definir os objetivos, selecionar um método para enquadrar a mensagem;

- Estrutura: Uma estrutura clara facilitará a percepção, interpretação, compreensão, aprendizagem e memória.

- Clareza: A legibilidade de uma mensagem gráfica é determinada pelo desenho técnico de palavras, textos e imagens, ou seja, sua clareza. Em geral, pode-se afirmar que a informação deve ser clara, simples, inequívoca e transparente. 
- Simplicidade: A leiturabilidade de uma mensagem gráfica é determinada pelo conteúdo e sua apresentação. O uso linguístico, bem como o estilo, deve ser correto para evitar distrair os leitores.

- Ênfase: A ênfase pode ser usada para chamar a atenção e mantê-la ou dramatizar certos pontos dos materiais informativos. A tipografia e o layout mostrarão a estrutura e a hierarquia do conteúdo do material informativo quando partes importantes forem enfatizadas.

- Unidade: Os conjuntos de informações devem ter unidade, uma "união geral". Todos os tipos de inconsistências em um material podem confundir os receptores. Pode se tornar desnecessariamente complicado para eles interpretar e entender o conteúdo pretendido da mensagem.

Dentre os Princípios Estéticos encontram-se:

- Harmonia: Certos elementos de design ficam bem quando colocados juntos. Outros elementos de design podem parecer feios e distrair. Existe harmonia em um material informativo quando todos os elementos de design se encaixam bem e formam relacionamentos harmoniosos.

- Proporção: O conceito de proporção estética é muito subjetivo. Podemos todos ter ideias diferentes sobre o que achamos bonito. Durante séculos, as proporções de acordo com a "proporção áurea" foram consideradas belas e muito importantes na arquitetura, na arte, no design e na tipografia. A proporção áurea tem o status de uma "regra de design". Essa regra, no entanto, não está de acordo com as opiniões expressas por sujeitos que participaram de "experimentos de proporção estética".

Dentre os Princípios Cognitivos encontram-se:

- Atenção: Um dos primeiros problemas do designer de mensagem é ganhar a atenção dos membros do público e, a partir daí, ele tem o problema contínuo de prender a atenção deles. Qualquer conjunto de informações e qualquer apresentação deve constantemente redesenhar a atenção para manter o interesse do espectador. Uma apresentação pode prender a atenção do espectador quando o ritmo e o layout não são previsíveis e muito enfadonhos.

- Percepção: Organizamos e analisamos as informações às quais prestamos atenção. Cores, ilustrações, linhas, imagens, sons, símbolos, textos e palavras devem ser integrados de forma que possam ser interpretados como um todo significativo em vez de uma série de elementos individuais.

- Processamento: Não há correspondência direta entre grupos de letras, palavras e realidade. Cada significado é definido na sociedade e deve ser aprendido. Compreender os conceitos que as palavras representam pode ser difícil para um não especialista. 
- Memória: Nossa memória de curto prazo é limitada e pode conter apenas alguns "pedaços de informação" ao mesmo tempo. Portanto, as informações devem ser cuidadosamente organizadas. A memória para imagens é superior à memória para palavras. Isso é chamado de "efeito de superioridade pictórica". Os recursos visuais podem fortalecer a fluência da linguagem, melhorando a memória e a recordação, além de fornecer um esquema visual no qual as informações podem ser organizadas e estudadas.

A infografia tem muito a contribuir para facilitar o acesso à informação, já que muitas vezes nos esquecemos que a leitura de informações textuais não é algo nato, e sim, aprendido de forma repetitiva, através de instruções e prática. $O$ fato da maioria dos adultos serem alfabetizados faz pensarmos que isso ocorre de forma automática. No geral, ícones pictóricos ou imagens simples são ótimos para informação de caráter didático e de assimilação rápida, como exemplos temos os infográficos e imagens de síntese.

\section{Infografia}

Para Pettersson (2010, p. 180) a infografia ajuda na absorção da informação já que "a memória para imagens é superior a memória textual" e nossos "receptores são mais capazes de construir conexões entre representações verbais e visuais quando o texto e as ilustrações são ativamente mantidos na memória ao mesmo tempo".

Apesar de ter surgido primeiramente nas revistas de Saúde, Ciência e Tecnologia e ser uma atividade que compete ao designer, a infografia, se tornou muito comum na área jornalística. Carvalho \& Aragão (2012) alertam que não é qualquer imagem seguida de texto ou legenda que pode ser considerada infográfico. A infografia é um sistema mais complexo que relaciona conteúdo com representação da informação, onde existe um elemento visual central (ou vários deles) acompanhado de textos explicativos.

Buljan et al. (2018) afirmam que resumos visuais e textuais de informações podem ser eficazes em termos de transferência de informações para diferentes público. As informações devem se adequar em termos de formato para capturar atenção dos leitores e acelerar o processo de conhecimento e assimilação.

Embora os infográficos possam ser desenvolvidos para muitos propósitos, eles são particularmente úteis como estratégia de ensino-aprendizagem por causa de seu potencial poder explicativo e de síntese (Chicca \& Chunta, 2020). Kanno (2013) acredita que algumas vezes o infográfico é a melhor maneira de representar certo tipo de informação, tendo uma enorme vantagem porque se diferencia do texto convencional e valoriza a pauta.

Buljan et al. (2018) examinaram o efeito de diferentes formatos (infográfico, resumo em linguagem simples e resumo científico) de informações sobre saúde na percepção dos estudantes, médicos e consumidores. Os três diferentes tipos de participantes preferiram a informação no formato de infográfico e deram a este tipo a classificação mais alta para experiência de leitura e considerado mais amigável. 
Por isso, faz-se necessário produzir documentos que sejam "compreensíveis, recuperáveis com rapidez e precisão, e fáceis de se traduzir para uma ação efetiva". O Design de informação "facilita a transferência de conhecimento ao tornar a informação, fornecida por aqueles que a sabem, acessível e compreensível àqueles que não a sabem, mas desejam saber" (Quintão \& Triska, 2014, p. 110).

\section{Métodos e Técnicas}

Para o desenvolvimento do infográfico foi utilizado o modelo proposto por Carvalho \& Aragão (2012, p. 175) (Figura 1).

Figura 1: Etapas e procedimentos para criação do infográfico. Fonte: (Carvalho \& Aragão, 2012).

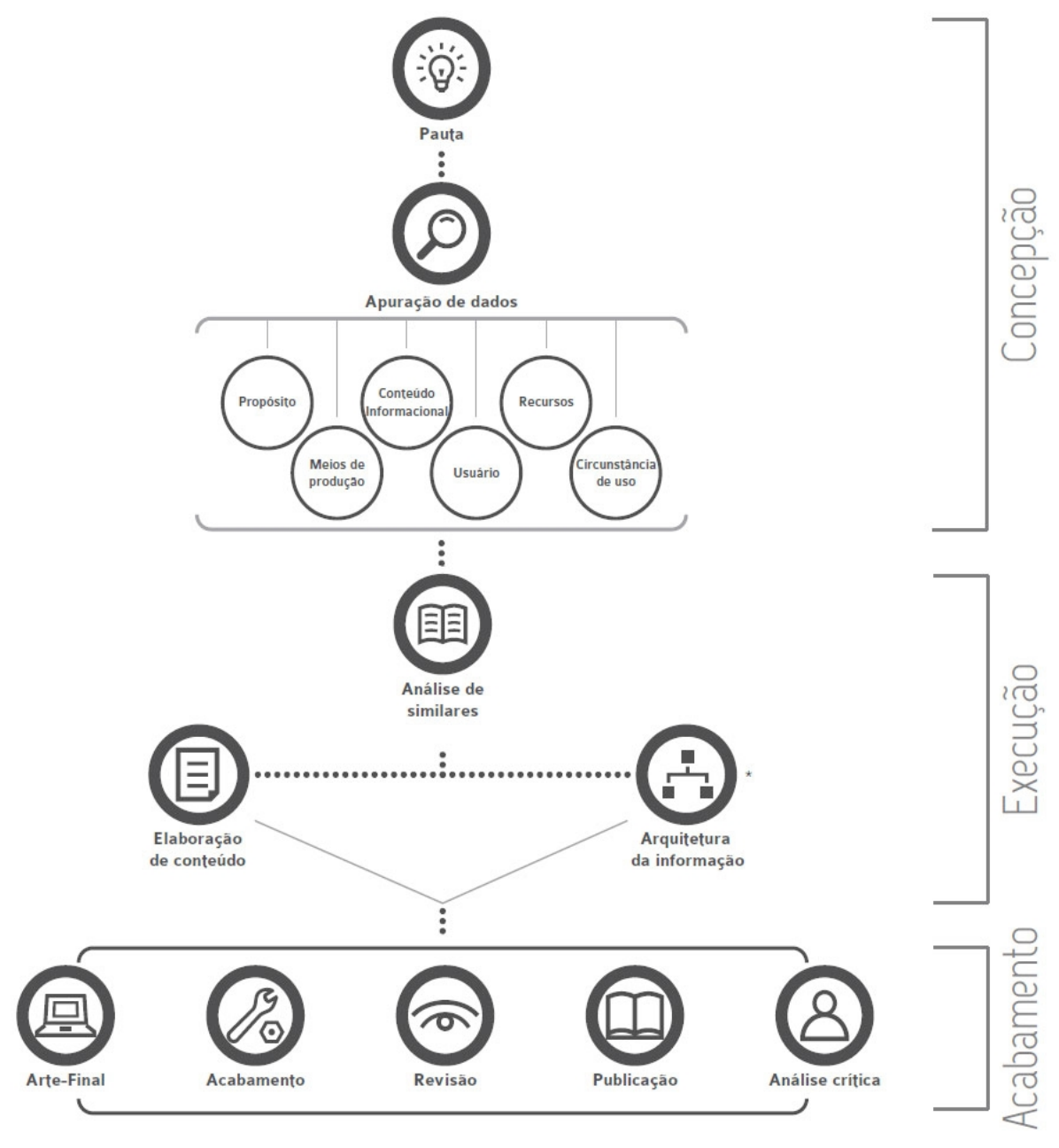

A Figura 1 apresenta as etapas de desenvolvimento do infográfico. A primeira etapa foi a de Concepção a qual se iniciou com a definição da pauta. A definição do tema foi sugerida pelos servidores ao levantarem os problemas recorrentes de cunho informacional que a criação da nova vara estava ocasionando. 
Este primeiro levantamento foi realizado através de entrevistas e foi possível compreender as principais dificuldades vivenciadas e expectativas quanto ao desenvolvimento do artefato. Desta fase participaram 5 (cinco) servidores da Vara de Saúde da Comarca de São Luis-Ma.

Como resultado desta fase obteve-se o tema a ser discutido e publicado, foi possível também compreender o problema e descrever o propósito do infográfico, os recursos disponíveis, o contexto de uso, os leitores e os meios de produção.

A segunda etapa foi a de Execução a qual iniciou-se pela pesquisa e análise de similares e inspirações estéticas. Na sequência seguiu-se para a elaboração de conteúdo, construção da arquitetura de informação para construção do leiaute.

A terceira e última etapa foi a de Acabamento na qual se fez a produção da arte final e detalhes como acabamento. Fez-se então a revisão final do artefato. Após discussões e análise crítica junto aos servidores, realizaram-se novos ajustes e então o mesmo pode ser publicado.

O presente estudo foi realizado nos meses de julho e agosto de 2020 e em virtude da pandemia ocasionada pelo vírus da COVID-19 e a impossibilidade da realização de encontros presenciais, todas as entrevistas para coleta de dados bem como as análises foram feitos à distância, por intermédio de aplicativos de mensagens e videoconferências.

\section{Resultados}

\section{Etapa 1: Concepção}

A pauta definida pelos servidores foi a respeito da implantação de uma nova Vara de Saúde Pública. Os problemas recorrentes de cunho informacional que a criação da nova vara estava ocasionando foram relatados pelos servidores que informaram que muitos processos errados estavam sendo encaminhados frequentemente para a vara em questão.

Segundo os servidores: "A vara é especializada em saúde pública (SUS) e está caindo muita demanda contra o 'particular'. Como por exemplo, hospitais particulares e até companhia de energia (devido a um paciente doente que necessitava de energia em seu domicílio)".

Ou ainda nos seguintes casos relatados: "alguns processos são de saúde pública, mas são de outra especificação, como, por exemplo, relacionados à infância e juventude. Esses processos devem ser encaminhados à vara de Infância e juventude e não para a vara de saúde."

Outro caso que estava gerando confusões é que a vara deveria tratar apenas de casos em que "as ações são contra o Estado e contra os municípios da <omitido para revisão cega> não cabendo processos contra municípios do interior".

Finalmente, outro problema apontado por um servidor é que "processos de demanda coletiva também estavam sendo encaminhados à vara, entretanto a competência era apenas para os processos cuja a demanda é individual, quando a demanda é coletiva, a competência para julgar é da vara de interesses difusos e coletivos, não nossa", relatou.

Em síntese, as principais dificuldades vivenciadas tangenciavam o encaminhamento de processos errados para a vara o que demandava um aumento da carga de trabalho já que todos os processos necessitam ser avaliados antes de serem encaminhados para a vara 
correta. A expectativa era possuir um conteúdo de síntese que orientasse os servidores e os usuários quanto às competências da vara dirimindo os conflitos de informações e expectativas.

Diante desse anseio, um quadro (Figura 2) foi feito por um servidor na tentativa de sintetizar tais informações, entretanto, o quadro servia de orientação apenas para os servidores que já possuíam compreensão do assunto, os demais usuários continuariam confusos quanto às competências da vara e quanto ao encaminhamento correto dos processos.

Figura 2: Quadro desenvolvido por um servidor da vara de saúde. Fonte: Dos autores

\begin{tabular}{|c|c|c|}
\hline \multicolumn{3}{|c|}{ Competência } \\
\hline \multirow{2}{*}{$\begin{array}{l}\text { Distribuição } \\
\text { do processo }\end{array}$} & $\begin{array}{c}\text { Antes de } \\
05 / 04 / 2019\end{array}$ & $\begin{array}{c}\text { Processo permanece na } \\
\text { Vara originária }\end{array}$ \\
\hline & $\begin{array}{l}\text { Depois de } \\
05 / 04 / 2019\end{array}$ & Vara de Saúde Pública \\
\hline \multirow{2}{*}{$\begin{array}{c}\text { Interesse de } \\
\text { menores }\end{array}$} & Sim & $\begin{array}{l}1^{\text {a }} \text { Vara da Inf ância e } \\
\text { Juv entude }\end{array}$ \\
\hline & Não & Vara de Saúde Pública \\
\hline \multirow{2}{*}{$\begin{array}{l}\text { Interesse de } \\
\text { idosos }\end{array}$} & Sim & $\begin{array}{c}\text { Vara especial do Idoso e de } \\
\text { Registros Públicos }\end{array}$ \\
\hline & Não & Vara de Saúde Pública \\
\hline \multirow{2}{*}{ Polo ativo } & $\begin{array}{l}\text { Demandas } \\
\text { coletiv as }\end{array}$ & Varas civeis \\
\hline & $\begin{array}{l}\text { Demandas } \\
\text { individuais }\end{array}$ & Vara de Saúde Pública \\
\hline \multirow[t]{2}{*}{ Polo passivo } & $\begin{array}{l}\text { Entidades } \\
\text { priv adas de } \\
\text { saúde. }\end{array}$ & Varas civeis \\
\hline & $\begin{array}{l}\text { Estado e } \\
\text { município }\end{array}$ & Vara de Saúde Pública \\
\hline
\end{tabular}

Desta forma foi possível definir o propósito do infográfico, o qual consistiria em orientar os usuários (servidores e demais interessados) quanto às competências da vara e fornecer informações quanto aos outros tipos de processos relacionados à saúde e seu correto encaminhamento.

O contexto de uso foi definido considerando a demanda atual que conforme os servidores era de disponibilizar com certa urgência essas informações através de dispositivos móveis utilizando as redes sociais e aplicativos de mensagens para compartilhar o mais rápido possível estas informações de uma maneira atrativa e simples, para melhor compreensão do assunto. Posteriormente, em decorrência do retorno gradual das atividades presenciais, este artefato deveria ser anexado também no formato impresso nas instalações físicas e de acesso à vara.

\section{Etapa 2: Execução}

A pesquisa de similares buscou infográfico de processos, considerando que o conteúdo informacional seria trabalhado em etapas. A pesquisa retornou diversas possibilidades e inspirações estéticas. Na sequência seguiu-se para a elaboração de conteúdo, construção da arquitetura de informação para construção do leiaute. 
Para isso utilizou-se como referência alguns princípios norteadores do Design da Informação sugeridos por Pettersson (2010). Dentre estes princípios encontram-se os Funcionais, os Estéticos e os Cognitivos para os quais são descritos os seguintes resultados.

Quanto à Definição do Problema e definição do conteúdo tem-se:

- Título Principal: Você conhece a Vara de Saúde Pública?

- Subtítulo Principal: Criada pela lei complementar XXXX e instalada em 15.07.2020.

- Conteúdo 1: Competências da Vara.

- Conteúdo 2: Informações sobre a equipe e contatos.

- Conteúdo 3: Ações atendidas.

- Conteúdo 4: Contatos e localização

Quanto à estrutura e hierarquia da informação, foi definida a estrutura em blocos representados por balões de diálogo, a fim de facilitar a percepção e apreensão do conteúdo em etapas, considerando que uma estrutura clara facilita a percepção, interpretação, compreensão, aprendizagem e memória (Pettersson, 2010). Definiu-se e limitou-se o número de níveis na estrutura. A hierarquia da informação foi delimitada a partir do tamanho das fontes e disposição dos títulos e subtítulos.

Quanto à clareza, para alcançar boa legibilidade da mensagem gráfica buscou-se a transmissão da informação de maneira clara e simples. As fontes selecionadas foram definidas considerando a clareza e a simplicidade.

Para a simplicidade os textos buscaram a boa leiturabilidade, para isso o uso linguístico almejou se distanciar de termos técnicos de difícil compreensão e sua disposição bem como dos elementos gráficos foram posicionados de maneira a evitar a distração dos leitores conforme orientações de Petterson (2010).

A ênfase foi utilizada para chamar atenção a elementos específicos como os títulos dos conteúdos. Utilizaram-se cores de destaque para os títulos e elementos gráficos como balões de conversa para destaque dando ênfase ao que era mais importante e para dar direcionamento à ordem da leitura. A figura humana foi utilizada para dar destaque à ideia de conversa e comunicação aproximando o usuário do servidor através da representação gráfica.

A unidade foi utilizada para que a leitura fosse realizada em etapas e assim o conteúdo complexo fosse assimilado aos poucos. Para a harmonia deu-se especial atenção à padronização de cores e alinhamentos em cada bloco de conteúdo.

Para isso foi desenvolvido um padrão para que todos os blocos possuíssem a mesma "massa" de conteúdo, proporcionando harmonia visual como sugerido por Petterson (2010).

Quanto aos princípios cognitivos para atrair a atenção dos leitores, buscou-se criar um título convidativo a fim de convocar o leitor ao interesse pelo conteúdo. Trabalhou-se também um ritmo e layout previsível, porém dinâmico, para isso alternou-se o alinhamento de cada bloco, mantendo o padrão harmônico.

Para facilitar a atenção humana, na hierarquia da informação trabalhou-se a definição do tamanho das fontes (tamanhos maiores para os textos mais importantes), espaços em branco 
(padronizados quando possível) e contrastes (figura e fundo), tais recursos buscaram atrair o olhar e prender a atenção dos leitores.

No critério Percepção as cores foram definidas considerando o assunto tratado (Judicialização da Saúde no Brasil) por isso buscou-se contrastes de verde e amarelo para compor a série de elementos visuais integrados na busca de um todo significativo.

E finalmente para atender ao princípio cognitivo do Processamento, considerando que compreender os conceitos que as palavras representam pode ser difícil para um não especialista (Pettersson, 2010), buscou-se simplificar a linguagem. Além disso, os elementos visuais buscaram complementar o assunto tratado a fim de contribuir na interpretação do assunto abordado.

\section{Etapa 3: Acabamento}

A última etapa contou com o Acabamento. Fez-se então a produção da arte final, inserção do conteúdo e detalhes finais. Após o desenvolvimento foi enviado aos servidores que solicitaram a mudança de alguns termos e a inclusão dos canais de contatos. O resultado pode ser visualizado na Figura 3. 
Figura 3: Infográfico desenvolvido. Fonte: Dos autores com base na pesquisa realizada.

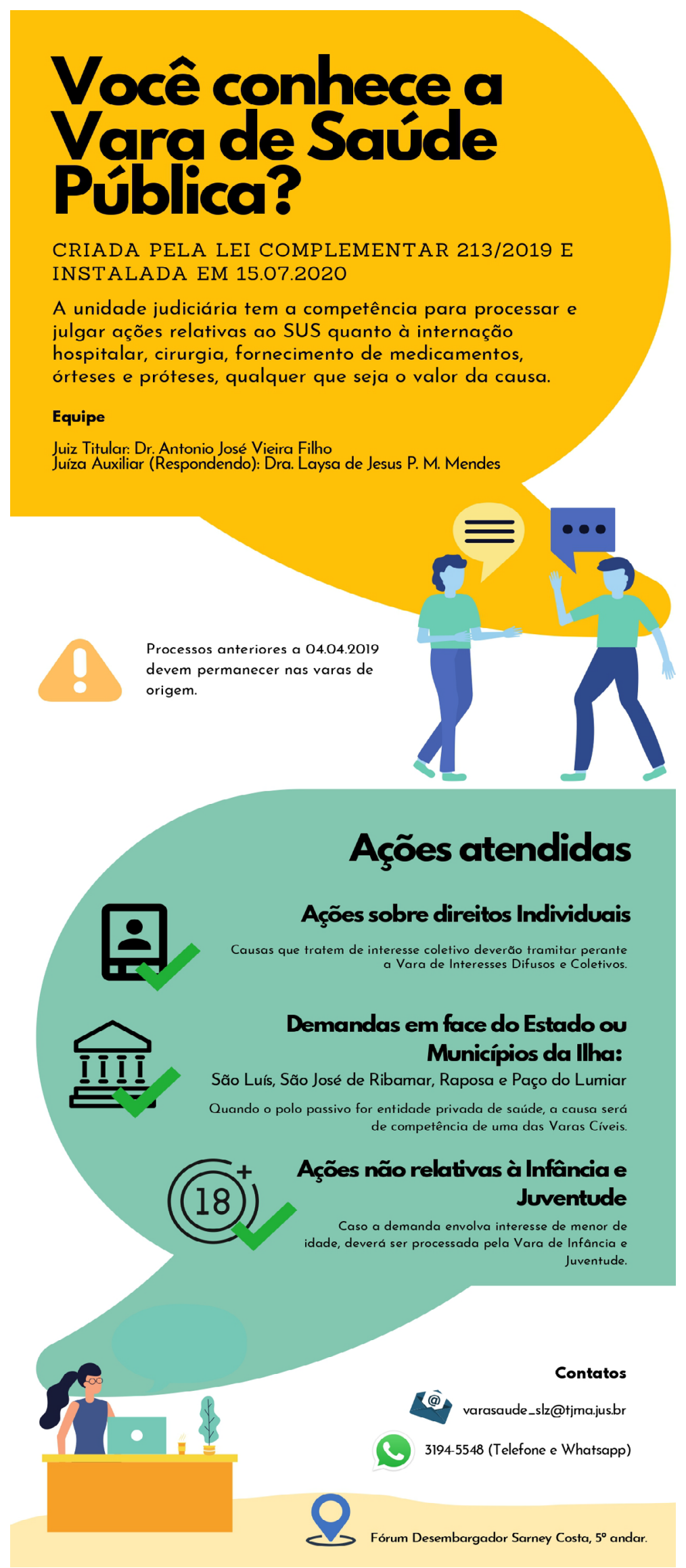




\section{Conclusões}

O propósito deste estudo foi ressaltar a importância do Design da Informação na intermediação de conflitos informacionais em um caso de implantação de uma nova vara especializada em saúde pública.

O infográfico desenvolvido a partir da captação das demandas relacionadas às dificuldades de cunho informacional, vivenciadas por servidores e usuários do sistema, permitiu a veiculação de uma informação de elevada complexidade de maneira simples, rápida e eficaz, através de smartphones, proporcionando, segundo os servidores, maior facilidade na compreensão das competências do setor, evitando assim erros e oportunizando maior celeridade aos trâmites dos processos.

Como reforça Agune \& Carlos (2019, p. 38) o uso das novas tecnologias móveis e aplicativos de rápida implementação viabilizam formas criativas de prestação de serviços que tornem mais cômoda a vida do cidadão, evitando deslocamentos que podem ser substituídos por entregas "a domicílio".

Tais entregas em domicílio foram essenciais no período de isolamento social em decorrência da pandemia ocasionada pelo vírus da COVID-19 em 2020, e após o retorno das atividades presenciais continuam sendo necessárias e oferecem um ganho de cunho inovador na comunicação usuário $x$ serviço do sistema judiciário.

A contribuição científica apresentada compreende a aplicação e experimentação prática da área do Design da informação e sua importância para diversos setores da sociedade da informação, mas sobretudo no que se refere aos serviços de inovação. Estudos futuros podem compreender as dificuldades e demandas de cunho informacional em demais setores do serviço público e contribuir para uma sociedade mais justa e igualitária no que se refere ao acesso à informação.

\section{Referências}

Agune, R., \& Carlos, J. A. (2019). Radar da inovação: o que os governos precisam enxergar. Em A. Gregório, Inovação no judiciário: conceito, criação e práticas do primeiro laboratório de inovação do poder judiciário (p. 236). São Paulo: Blucher.

Buljan, I., Malicki, M., Wagner, E., Puljak, L., Hren, D., Kellie, F., . . Marusic, A. (2018). No difference in knowledge obtained from infographic or plain language summary of a Cochrane systematic review: three randomized controlled trials. Journal of Clinical Epidemiology, 97, 86-94.

Carvalho, J., \& Aragão, I. (2012). Infografia: conceito e prática. Infodesign, 9 (3), 160-177.

Chicca, J., \& Chunta, K. (2020). Engaging Students with Visual Stories: Using Infographics in Nursing Education. Teaching and Learning in Nursing,15, 32-36.

Conselho Nacional de Justiça. (2016). Resolução 238 de 6 de setembro de 2016. Brasília, DF, BRASIL: Poder Judiciário. 
Dick, M. E., Gonçalves, B. S., \& Vitorino, E. V. (2017). Design de Informação e competência em informação: relações possíveis. Revista Brasileira de Design da Informação, 17 (1), 1 - 13.

Frascara, J. (2015). Information design as principled action: Making information accessible, relevant, understandable, and usable. Champaign: Common Ground Publishing.

Hagan, M. (s.d.). In this introductory chapter, I introduce the concept of 'Legal Design' \& define what Design and Design Thinking mean. Acesso em 20 de Janeiro de 2021, disponível em https://www.lawbydesign.co/legal-design.

Kanno, M. (2013). Infografe: Como e porque usar infográficos para criar visualizações e comunicar de forma imediata e eficiente. São Paulo: Infolide.

Lipton, R. (2007). The practical guide to information design. New Jersey: Wiley.

Medrado, R., Cruz, M. G., Raso, L. M., \& Rocha, H. H. (2013). SOS SUS: Muita Justiça, Pouca Gestão? Estudo sobre a Judicialização da Saúde. Anais do XXXVII Encrontro da ANPAD. Fonte: http://www.mpdft.mp.br/saude/images/judicializacao/SOS_SUS.pdf.

Pettersson, R. (2010). Information Design: principles and guide-lines. . Journal of Visual Literacy, 29 (2),167-182.

PODER JUDICIÁRIO DO ESTADO DO MARANHÃO. (2020). COMARCA DA ILHA | Vara de Saúde Pública recebeu 178 processos no primeiro mês de funcionamento. São Luís, Maranhão. Acesso em 20 de janeiro de 2021, disponível em https://www.tjma.jus.br/midia/portal/noticia/500449

Quintão, F., \& Triska, R. (2014). Design de informação: origens, definições e fundamentos. . Infodesign, 11 (1),105 - 118.

SOCIEDADE BRASILEIRA DE DESIGN DA INFORMAÇÃO (2020). Definições. Brasil, Disponível em: <http://www.sbdi.org.br/definicoes>. Acesso em: 20 de Janeiro de 2021.

Zanoni, O. (2019). A mudança cultural da gestão judicial: inovação como base da busca da excelência do serviço público. Em Á. Gregório, Inovação no judiciário: conceito, criação e práticas do primeiro laboratório de inovação do poder judiciário (p. 236) São Paulo: Blucher.

\section{Sobre os autores}

Lívia F. de Albuquerque Campos, Dra. UFMA, Brasil, livia.albuquerque@ufma.br Fabiane Rodrigues Fernandes, Dra. UFMA, Brasil, fabiane.fernandes@ufma.br

Francisco H. Garces de Albuquerque, Esp., TJMA, Brasil, fhgalbuquerque@tjma.jus.br 